\title{
Navigation mechanisms of herring during feeding migration: the role of ecological gradients on an oceanic scale
}

\author{
Cecilie Broms $^{\mathrm{a}, *}$, Webjørn Melle ${ }^{\mathrm{a}}$ \& John K. Horne ${ }^{\mathrm{b}}$
}

\author{
a Institute of Marine Research, P. O. Box 1870 Nordnes, 5817 Bergen, Norway. \\ ${ }^{b}$ University of Washington, School of Aquatic and Fisheries Science, Box 355020, Seattle, WA 98195, USA. \\ *: Corresponding author : Cecilie Broms, email address : cecilieb@imr.no
}

\begin{abstract}
:
The feeding migration of Norwegian spring-spawning herring was studied in relation to prey abundance and environmental factors that may affect their feeding migration. Temperature, salinity, chlorophyll a, nitrate concentration, abundance of Calanus finmarchicus, zooplankton biomass, acoustic data on herring and trawl samples were collected during four basin-scale surveys in the Norwegian Sea from April to August 1995. Herring abundance was positively associated with the overwintering population of $C$. finmarchicus. We suggest that spatial gradients and temporal dynamics of the seasonal ascent of the $C$. finmarchicus overwintering generation provide stimuli for and affect the feeding migration of herring. The clockwise migration pattern of herring, observed during the 1990s, can be explained by delayed ascent and development of $C$. finmarchicus toward the west and north in the Norwegian Sea. We further suggest that herring leave a specific area before their zooplankton prey is depleted. The first generation of $C$. finmarchicus likely has a minor influence in directing the herring feeding migration due to the low abundance of older stages available as prey. The feeding migration was constantly directed toward colder water, and temperature probably has a secondary effect on herring distribution
\end{abstract}

Keywords: Calanus finmarchicus ; feeding migration ; herring ; predator-prey interactions ; Norwegian Sea ; reactive mechanisms 


\section{Introduction}

Heterogeneous distributions of environmental conditions and organisms are characteristic traits of aquatic ecosystems. Planktivorous fish such as Norwegian spring spawning herring (Clupea harengus Linnaeus, 1758) can sense physical and biological gradients and respond to changes in concentrations of potential prey and environmental conditions. Response to favourable conditions following reactive orientation mechanisms (sensu Fernö et al., 1998) potentially concentrates nektonic species in preferred habitats. Observed herring distribution patterns may spatially and temporally index reactions towards environmental (e.g. temperature and salinity) and biological (e.g. prey distribution) factors. Genetic factors and learning (predictive orientation mechanisms) may also affect herring migration patterns (Fernö et al., 1998).

Population abundances and migration patterns of Norwegian spring spawning (NSS) herring have changed over the last century (Dragesund et al., 1997; Toresen and Østvedt 2000). After the stock collapse of NSS herring at the end of the 1960s, herring fed along the Norwegian coast, most frequently in the Lofoten and Vesterålen areas off northern Norway (Dragesund et al., 1997). In the second half of the 1980s the NSS herring stock abundance increased and the feeding migration gradually extended further offshore from the Norwegian coast (Holst et al., 2002). During the 1990s, NSS herring resumed the feeding migration pattern prior to the stock collapse, in the central and western parts of the Norwegian Sea (Dragesund et al., 1997; Misund et al., 1997; Holst et al., 2002).

Following the migration pattern of the 1990s, mature herring spawned on the coastal banks of Norway in February-March prior to the feeding migration (Holst and Slotte, 1998). By mid-May the spawning stock had spread westwards over large parts of the Norwegian Sea (Holst et al., 2004). The western limit of herring distribution as observed during spring was the Arctic front, which may act as a physiological barrier due to low spring temperatures $\left(1-2^{\circ} \mathrm{C}\right)$ on the west side of the front (Misund et al., 1997, 1998). Mature herring followed the front northwards in late May and June (Misund et al., 1998) before migrating north-east in July-August, and then returning to the overwintering area in the Lofoten region in late August and September (Misund et al., 1998; Holst et al., 2002).

During their clockwise feeding migration in the Norwegian Sea, NSS herring are envisaged to experience consistent and predictable water mass traits and timing of seasonal plankton production (Fernö et al., 1998). Three water masses constitute the Norwegian Sea surface water and differ in physical, chemical and biological features (Skjoldal, 2004). Coastal water situated in the eastern Norwegian Sea flows northwards over the Norwegian shelf and is characterized by a strong seasonal thermal cycle and salinity below 35. Above the shelf break, a relatively fixed front separates the Coastal and Atlantic water. Atlantic water, characterized by temperatures above $6.5^{\circ} \mathrm{C}$ and salinity above 35 enters the Norwegian Sea through the Faroe Islands-Shetland channel and across the Faroe Ridge (Blindheim, 2004). Atlantic water passes northwards through the central Norwegian Sea and enters the Barents Sea and the Arctic Ocean (Blindheim, 2004). The colder $\left(<3^{\circ} \mathrm{C}\right)$ and less saline Arctic water dominates the western Norwegian Sea. The Arctic front separates the Atlantic and Arctic waters and while the location of the front is relatively fixed over the mid-Atlantic ridge north of Jan Mayen, strong interannual longitudinal fluctuations in accordance with climate variability are present in the south (Blindheim et al., 2000; Blindheim, 2004). 
In the Norwegian Sea, Calanus finmarchicus (Gunnerus, 1770) is the dominant zooplankton species in terms of biomass (Wiborg, 1955; Timokhina, 1964; Melle et al., 2004) and the primary prey of NSS herring (Dalpadado et al., 2000; Gislason and Astthorsson, 2002; Prokopchuk and Sentyabov, 2006). The Calanus life cycle consists of egg, six naupliar, and six copepodite stages ( $\mathrm{Cl}$ to $\mathrm{CVI}$ ), where $\mathrm{CVI}$ is the adult stage. Sub-adult copepods (mainly stage CV) overwinter in deep water and ascend to surface waters to spawn in late winter and early spring (Melle et al., 2004). A delayed reproduction of $C$. finmarchicus from Coastal water to Atlantic and Arctic waters has been observed and linked to the phytoplankton spring bloom development that follows the same pattern (Broms and Melle, 2007; Stenevik et al., 2007). Earlier investigations have suggested a one-year lifecycle of $C$. finmarchicus in the northern and western part of the Norwegian Sea, while two or more consecutive generations can be produced annually in south and east (Wiborg, 1954; Østvedt, 1955; Broms and Melle, 2007).

There is a long history of research on size selective predation by NSS herring on $C$. finmarchicus (Dalpadado et al., 2000; Gislason and Astthorsson, 2002; Prokopchuk and Sentyabov, 2006). Østvedt (1965) observed that older age groups of NSS herring feed on older stages of $C$. finmarchicus, and suggested that this was related to migration by herring into areas where larger specimens of the overwintering generation were abundant. When entering the colder mixed Atlantic/Arctic water, a higher proportion of $C$. hyperboreus is found in their diet (Dalpadado et al., 2000).

Predictability of the environment, such as the trajectory of seasonal zooplankton production in different water masses, may provide habitat characteristics that influence the evolution of predictive orientation mechanisms (see Fernö et al., 1998). However, herring also experience variability within water masses that are driven by atmospheric and oceanographic processes, which may cause herring to react to local conditions during the migration. In the present study we examine prey field and environmental qualities that may influence the direction and distribution of NSS herring during the feeding migration. The seasonal ascent of the overwintering generation of $C$. finmarchicus will increase the herring prey densities. It has been shown that the abundance of the overwintering Calanus finmarchicus population is highest during the pre-bloom period (Niehoff et al., 1999; Broms and Melle, 2007; Stenevik et al., 2007), and that the bloom in the Norwegian Sea is delayed towards the west and north (Broms and Melle, 2007). We hypothesize that Norwegian spring spawning herring migrate toward areas that are in a pre-bloom phase with high abundances of the overwintering generation of $C$. finmarchicus. An expectation of this hypothesis is that the feeding migration will be delayed in the western and northern areas of the Norwegian Sea and that herring density will correlate with the density of the overwintering population of $C$. finmarchicus. To explain the feeding migration of herring by this bottom-up approach, several trophic levels need to be examined. We will explore how the seasonal cycle of $C$. finmarchicus responds to the environment and how the concentration of $C$. finmarchicus in turn affects herring migration.

\section{Material and methods}

Four cruises were carried out in the Norwegian Sea from April to August 1995 using the research vessels "G.O. Sars" and "Johan Hjort" (Figure 1). Temperature, salinity, nitrate, and chlorophyll a samples were collected at predetermined locations (Figure 1) using a rosette frame equipped with water bottles and a CTD (Neill Brown Mk III 1150 ) by vertical casts to $1000 \mathrm{~m}$ or bottom. Salinity at $20 \mathrm{~m}$ and sample location 
relative to the Atlantic water mass were used to categorise sampling stations in one of three water masses: Coastal water (salinity $<35$, sample location east of the Atlantic water mass), Atlantic water (salinity $\geq 35$ ) and Arctic water (salinity $<35$, sample location west of the Atlantic water mass). Laboratory analyses of nitrate and chlorophyll a were performed according to Hagebø and Rey (1984). The amount of nitrate consumed after winter mixing was used as a proxy for phytoplankton development in the Norwegian Sea (Broms and Melle, 2007). At each sampling station, consumed nitrate $\left(\mu \mathrm{mol} \mathrm{L} \mathrm{L}^{-1}\right)$ was calculated as the depth-integrated winter nitrate values minus the depth-integrated amount of nitrate in the upper $100 \mathrm{~m}$. Winter nitrate values were defined as the highest nitrate value observed within the upper $100 \mathrm{~m}$ of each water mass from March through August: $12.6 \mu \mathrm{mol} \mathrm{L^{-1 }}$ Coastal, $12.9 \mu \mathrm{mol} \mathrm{L}{ }^{-1}$ Atlantic, and $11.6 \mu \mathrm{mol} \mathrm{L}{ }^{-1}$ Arctic water. These values matched earlier published winter nitrate values (Rey, 2004; Fransisco Rey pers. com. 2005; Institute of Marine Research, Bergen, Norway).

Zooplankton samples were collected at the hydrographic stations, taken from the bottom to the surface by oblique hauls with MOCNESS $(180 \mu \mathrm{m}$ mesh size $)$ in four depth strata: 0-25 m, 25-50 m, 50-100 m, and 100-200 m. Each zooplankton sample was split into two equal parts: one preserved in $4 \%$ formaldehyde and used for taxonomical analyses; the other for biomass measurements. Zooplankton samples were identified to the lowest taxonomic level possible. Calanus species were classified to copepodite stage and sex was determined for adult animals. Our hypothesis is that the Norwegian spring spawning herring migrate toward areas that are in a pre-bloom phase with high abundances of the overwintering generation of $C$. finmarchicus. In the further analysis $C$. finmarchicus overwintering generation was represented by the copepodite stages $\mathrm{V}$ and $\mathrm{VI}$, where $\mathrm{V}$ is the main overwintering stage developing into VI males and females. Copepodite stage IV was included when the relative importance of the overwintering and first generation of $C$. finmarchicus in directing the herring feeding migration was investigated by looking at the seasonal development of the older copepodite stages. Copepodite stage I-III, representing the first generation, are only to a very small extend found in the diet of herring and is not included in the analysis. Calanus densities in the upper $200 \mathrm{~m}$ of the water column are presented as number of animals per square metre (Nos. $\mathrm{m}^{-2}$ ). The biomass was measured by sieving the samples into three different size fractions: one larger than $2000 \mu$, the second from $1000 \mu$ to $2000 \mu$, and the third from 180 to $1000 \mu$. The biomass fractions were oven-dried at $70^{\circ} \mathrm{C}$ for more than 24 hours and the dryweight measured. The biomass size fractions were included in the analyses to understand potential effects of zooplankton prey organisms other than $C$. finmarchicus.

The distribution of herring was continuously mapped using a calibrated $38 \mathrm{kHz}$ Simrad EK 500 echosounder. The acoustic data were scrutinised and stored at the horizontal resolution of five nautical miles. Herring abundances are presented as nautical area scattering coefficients $\left(\mathrm{s}_{\mathrm{A}}\right.$-values, $\left.\mathrm{m}^{2} \mathrm{nmi}^{-2}\right)$ averaged over 5 nautical miles. At predetermined locations or according to acoustic registrations, an Åkra trawl (see Valdemarsen and Misund, 1995) with a $30 \mathrm{~m} \times 30 \mathrm{~m}$ mouth opening was towed at 3-4 knots to obtain herring samples. $S_{A}$-values were allocated to species according to the appearance of echo recordings and in comparison with trawl catches, and in accordance with routines at Institute of Marine Research for fisheries stock assessment cruises. Length and age of approximately 100 herring were measured from a random sub-sample taken from each trawl catch. At predetermined trawl stations and when trawling was aimed at acoustic registrations, hydrographic and zooplankton data were obtained in close vicinity to the trawl station. Some surveys covered large parts of the migration area while at other times only fractions of the 
herring stock was covered. Total geographical coverage of the herring distribution is not the major objective of the present study, but to generate large scale gradients into the core feeding areas of the herring and to resolve the temporal (seasonal) changes in migration and feeding. Acoustic data on herring ( $\mathrm{s}_{\mathrm{A}}-\mathrm{v}$ alues) are presented in Figure 2 illustrating the herring distribution within survey periods and the survey area covered. Mapping was done in ArcGis10. Salinity isohalines were calculated based on interpolation (inverse distance weighted (IDW)) of salinity measurements at the stations. Methods used in the quantitative herring analyses are described in the following paragraphs.

Herring density (number of herring per square nautical mile, $\rho_{A}$ ) was estimated by proportioning $S_{A}$ values into fish length classes. Because the acoustic backscatter coefficient is dependent on fish length, herring length distributions obtained from trawl catches were used to allocate $s_{A}$ values to length groups within $0.5 \mathrm{~cm}$ intervals. The calculations were done in accordance with Misund et al. (1998) using the target strength (TS) to fish length relationship for herring from Foote (1987).

Herring were divided into young ( $<5$ years old) and old ( $\geq 5$ years old) age components to separate young herring with a shorter migration route from the older herring with a more extensive migration. The age of five years was chosen to separate the two components based on historical migration routes and maturation age (Dragesund et al., 1980, 1997; Misund et al., 1997, 1998; Anon., 1995). The young and old components correspond to immature and mature herring, respectively. Variation in age at maturation (Dragesund et al., 1980) may cause a slight mixing of maturation stages between the two age groups. The total number of herring per square nautical mile was calculated for each of the two age groups. Only the mature herring component was used in the analyses due to the different feeding areas and migration route compared to the immature herring component, and thus potential diverging responses to environmental variables and signals governing the feeding migration. For the further analyses, zooplankton and environmental data at each station was related to the abundance of mature herring in a confined area of $5 \mathrm{~nm}$.

Generalized additive models (GAMs) were used to investigate relationships between herring abundance and environmental conditions, and between Calanus finmarchicus abundance and environmental conditions. GAM extends generalised linear regression by fitting nonparametric functions estimated from the data using smoothing operators (Hastie and Tibshirani, 1990; Zuur et al. 2007). First, single explanatory variable models were formulated (Gaussian error distribution, identity link function). No maximum degrees of freedom acceptable for the predictors were predefined. Second, multiple explanatory variable models were selected. Backwards model selection, a method that consecutively drops the least significant remaining term from the current model until only significant terms are left, was used in model formulation (Zuur et al. 2007). Additionally, model selection was based on generalized cross validation (GCV) score, which considers both fit and complexity of a model, enabling models to be compared (Wood, 2006). Models with lowest GCV scores represent the most parsimonious model. A thin plate regression spline was used as smoother (Wood, 2003). To allow, based on the number of stations, the inclusion of all the explanatory variables that was assumed to potentially affect the response variable in model selection, variables with linear effects in the single variable models were given one degree of freedom. Otherwise, no maximum degrees of freedom acceptable for the predictors were predefined. To assess collinearity when additive models with multiple explanatory variables were formulated, we used pairwise scatterplots, correlation coefficients, and variance inflation factors (VIF). Models with herring abundance as predictor: Biomass fraction 2 (which will include the biomass of Calanus finmarchicus copepodite stages IV and older) correlated 
highly with Calanus finmarchicus $(r=0.81)$ and was thus excluded from the multiple additive model analysis. Day of the year was also excluded from this analysis due to high VIF (15.7). All other variables had VIF values below 3.8, which were considered acceptable. Models with C. finmarchicus as predictor: Day of the year correlated highly with several other variables, especially temperature $(r=0.86)$, and had high VIF value (14.8) and was thus excluded from the analysis. All other variables had VIF values below 4.4, which were considered acceptable. Model validation was applied by using a number of standard residual plots to assess homogeneity, normality and influential observations (Zuur et al. 2007, Zuur et al. 2009). To meet model assumptions the variables Calanus finmarchicus abundance, herring abundance, biomass fractions and chlorophyll a were transformed using a log $(x+1)$ transformation (Legendre and Legendre, 1983).

Herring density was modelled conditionally on the acoustic response being greater than 0 . By modelling herring abundance excluding zero stations, important biological concerns regarding zero value stations will be omitted. The zero values can have several interpretations: Zero values of herring are observed in areas that the herring have grazed and left, and in areas that herring are about to invade. These categories of zero $\mathrm{s}_{\mathrm{A}}$-value stations would be problematic to separate in the analyses. Zero value stations would additionally include areas that the herring with the known migration pattern of the time period in question (Holst et al., 2002) would not invade. We can in some cases distinguish zero values in waters ahead of the herring migration front, however we see no means to correctly distinguish all these conditions, thus an inclusion of these areas would most likely make the interpretation of the results more difficult.

\section{Results}

\subsection{Distribution of herring during feeding migration}

Figure 2 shows the $s_{A}$ values of herring from the parts of the herring distribution covered by the surveys. The four surveys covered to a varying extent the herring feeding migration. In the following we describe the herring feeding migration at the time of the surveys based on previously published results on migration, with the aim to clarify to what extent we were able to obtain data from the core feeding areas of herring at different times during its feeding season: Norwegian spring spawning herring cycled through large parts of the Norwegian Sea during the feeding migration in 1995. Larger and older herring migrated farther west and north than younger individuals. In April the highest concentrations of the old component of NSS herring were found in the central and eastern Norwegian Sea, approximately between $65^{\circ}$ and $68^{\circ} \mathrm{N}$ (Figure 2a; Anon., 1995). In an area west and southwest of Lofoten, herring acoustic recordings were obtained, but no trawling was conducted. Herring in this area are believed to be composed of younger animals. The old herring component (mainly the year classes 1983, -89 and -90 (Anon., 1995)) migrated west and north in the Norwegian Sea. In late May and June older herring were distributed on the eastern side of the Arctic front and along the front of mixed Atlantic/Arctic water southeast of Jan Mayen, mainly west of the $0^{\circ}$ meridian (Figure 2b; Anon., 1995; Misund et al., 1998). In July the old herring were observed north in the Norwegian Sea, west of approximately $10^{\circ} \mathrm{E}$ (Figure 2c). In August the older component had shifted east in the herring distribution area, and north of $70^{\circ} \mathrm{N}$ old herring dominated the samples. The northern border of the concentration was not defined in July and August (Figure 2d; Anon., 1995; Misund et al., 1998). Based on other studies of herring migration pattern from the time period in question (Anon., 
1995; Misund et al., 1998; Holst et al. 2002), the surveys in the present study did not fully cover the herring distribution, but core areas occupied by the stock throughout the feeding season. The survey lines went through areas with both low and high density of herring, covering large scale gradients of herring distribution several times during the season.

\subsection{Herring abundance and environmental variables}

The environmental variables assumed to be important for herring during their feeding season and therefore included in the generalized additive models (GAMs), are given in Table 1 along with an explanation for selecting these variables. The response of herring abundance to each of the single-term models is shown in Figure 3. Herring abundance was significantly related to longitude, Calanus finmarchicus CV-CVI and temperature (Table 2). Of the significant relationships, herring showed strongest association with older stages of $C$. finmarchicus, which explained $23 \%$ of the deviance in herring abundance, and an increase in $C$. finmarchicus abundance gave an increase in herring abundance (Figure 3). A negative association was observed between herring abundance and temperature, and between herring abundance and longitude, explaining $15 \%$ and $13 \%$ of the deviance respectively and giving an increase in herring abundance in colder water and towards the west of the feeding area.

Additive models with multiple explanatory variables were then formulated to improve the model. Running the backwards model selection, only $C$. finmarchicus was significant, and all other terms rejected as insignificant. However, the GCV scores suggested a multiple model consisting of $C$. finmarchicus, biomass fraction 3 and temperature as the best model (Table 2), explaining $51 \%$ of the deviance of herring abundance. The multiple model explained significantly more of the variation in herring abundance compared to the model containing only $C$. finmarchicus (ANOVA, $p<0.05$ ), and the effect of each explanatory variable is shown in Figure 4. The herring response to variations in biomass fraction 3 is not easily explained biologically due to the high degree of non-linearity and small zooplankton being less important as food. The response may be due to external environmental factors simultaneously affecting both herring and small zooplankton. An effect of biomass fraction 2 and day of the year in the multiple GAMs cannot be precluded as those variables were excluded from the analyses due to potential collinearity. In model validation, the QQ-plot and histogram of the residuals showed some deviation from normality. No increase in the spread of the residuals was observed, indicating that the homogeneity assumption was fulfilled. The Cook's distance plot showed all values well below 1.0 indicating no influential observations.

\subsection{Overwintering and new generation of Calanus finmarchicus.}

To examine the relative importance of the overwintering and first generation of Calanus finmarchicus in directing the herring feeding migration, GAMs were fitted $C$. finmarchicus copepodite stage IV, V and VI as response to day of the year (Figure 5). Highest abundances of $C$. finmarchicus CIV were observed in April and early May, which is the overwintering generation of $C$. finmarchicus. CIV abundance decreased until late June, and then slowly increased through the remainder of the season probably representing the first generation developing from CIII to CIV. Calanus finmarchicus CV abundance remained high until mid-July and decreased in the second half of July and August. The CIV in late season will develop into CV and the small increase in CV towards the end of the season, before the sharp decrease in abundance, probably contains individuals of the first generation. The sharp reduction of $\mathrm{CV}$ is due to seasonal descent of the first generation. The long period with high $\mathrm{CV}$ 
abundance in first half of the season represents the overwintering generation, and is probably due to sampling in a large area with different timing in the seasonal development of $C$. finmarchicus. The CVI had high abundance at the beginning of the season, representing the overwintering generation, and a decrease throughout the season. No second peak of CVI representing a first generation was observed, indicating a one-year life cycle in this area. Accordingly, most of the high abundance of $\mathrm{CV}$ and $\mathrm{CVI}$ represents the overwintering generation, but some of the high abundance of $\mathrm{CV}$ in late season may belong to the first generation.

\subsection{Calanus finmarchicus and environmental variables within the feeding area of herring}

Calanus finmarchicus have been suggested in the previous analyses to be an important factor governing herring density during the period of herring feeding migration, being the most important single variable and a term in the best model. To increase our understanding of how $C$. finmarchicus seasonal cycle may affect herring migration, environmental effects on $C$. finmarchicus abundance were explored (Table 3 , Figure 6). All variables except salinity were strongly related to $C$. finmarchicus abundance. Older stages of $C$. finmarchicus were most abundant at low chlorophyll $a$ concentrations, probably representing the pre-bloom period. Low chlorophyll a concentrations could also represent the post-bloom period or depletion of phytoplankton by the zooplankton. However, in those cases a primary production and consumption of nutrients would have taken place, while in the present situation high abundance of $C$. finmarchicus was concurrent with low values of consumed nitrate and additionally observed early in the season (Figure 6). The pre-bloom situation supports that this high concentrations of $C$. finmarchicus is the overwintering generation. Chlorophyll a concentrations explained $50 \%$ of the deviance in $C$. finmarchicus abundance. Highest density of older stages of $C$. finmarchicus was observed at low temperatures and in western parts of the Norwegian Sea (Figure 6).

To further explore the seasonal dynamic of Calanus finmarchicus additive models with multiple explanatory variables were formulated. Based on GCV scores a model consisting of temperature, salinity, chlorophyll $a$ and consumed nitrate was suggested as the best model (ANOVA, $p<0.05$ ), explaining $77 \%$ of the deviance of C. finmarchicus abundance (Table 3 ). The model indicates that the seasonal abundance of older stages of $C$. finmarchicus is affected by water mass (represented by temperature and salinity) and the seasonal development of phytoplankton (represented by chlorophyll $a$ and consumed nitrate). An effect of day of the year in the multiple GAMs cannot be precluded as this variable was excluded from the analyses due to potential collinearity.

\section{Discussion}

The overwintering generation of Calanus finmarchicus was the most important single factor and a main component in the best model explaining the distribution and density of herring in the investigated area. Herring abundance was positively related to the overwintering generation of Calanus finmarchicus. This supports our hypothesis that the overwintering generation of $C$. finmarchicus affects the feeding migration of herring. The seasonal ascent of $C$. finmarchicus after overwintering in deep waters, and subsequent development into the adult stage, increase potential prey densities in near surface waters and may provide stimuli for the feeding 
migration of herring. Development of $C$. finmarchicus is delayed toward west and north in the Norwegian Sea (Broms and Melle, 2007), and the delay may already be traced in the ascent of the overwintering population. Highest concentrations of the overwintering generation of $C$. finmarchicus were observed in the pre-bloom, which also is delayed toward west and north in the Norwegian Sea. Herring may continue to invade new areas of high concentrations of $C$. finmarchicus by following gradients of increasing prey densities through reactive orientation mechanisms. Due to potential collinearity and thus exclusion of biomass fraction 2 in the multivariate analysis, $C$. finmarchicus may also represent biomass fraction 2 (size fraction, 1-2 mm).

Knowledge of the timing of the ascent of the overwintering population of Calanus finmarchicus, and mechanisms causing the ascent are limited (Miller et al., 1991; reviewed by Hirche, 1996; Hind et al., 2000). Highest concentrations of the overwintering generation of $C$. finmarchicus in the pre-bloom (Fig. 6) indicates that the arrival of $C$. finmarchicus in the upper $200 \mathrm{~m}$ of the water column co-occur with the pre-bloom. Initiation of the phytoplankton production in the southeast and spreading to the northwest in the Norwegian Sea (Pavshtiks and Timokhina, 1972; Broms and Melle, 2007; Stenevik et al., 2007) thus indicates that the seasonal ascent of $C$. finmarchicus follows the same pattern. This is also supported by Melle et al. (2004) who suggested that the final stage of the ascent may be related to the initiation of phytoplankton production during the pre-bloom phase. Adult herring were found in central Atlantic water and toward the Arctic front in April (Figure 2a). This concurs with phytoplankton pre-bloom and observations of high density of overwintering stages of $C$. finmarchicus near the surface in Atlantic water (Niehoff et al., 1999; Hirche et al., 2001; Broms and Melle, 2007; Stenevik et al., 2007). During May, adult herring reach the western part of the Norwegian Sea, coexisting with high abundances of CIV to $\mathrm{CVI}$ of the overwintering population of $C$. finmarchicus (Melle et al., 2004). A subsequent migration of herring along the Arctic front (Figure 2b) northwards to areas southeast of Jan Mayen in June, agrees with a delayed development of $C$. finmarchicus in northern Atlantic water compared to the southern region (Broms and Melle, 2007).

Although NSS herring migrated northwards along the Arctic cold front in 1995, as was the general migration pattern in the 1990s when herring had resumed their feeding migration to large parts of the Norwegian Sea after the reduced feeding migration subsequent to the stock collapse (Misund et al. 1997, 1998, Holst et al. 2002), herring may also cross the Arctic front and feed in Arctic water. During warm periods (1950-1964) herring migrated westwards in May and June to feed in areas north of Iceland (Østvedt 1965, Jakobsson 1980, Dragesund et al. 1980). In recent years herring feeding migration have shown a southwestern trend and the western boundary of the herring distribution has been observed far into Arctic water in the Iceland Sea (ICES 2003, 2010). This western migration route may have been induced by poor feeding conditions of the eastern Norwegian Sea as indicated by the low zooplankton biomass in the east (ICES 2008). The role of different environmental factors in inducing a western herring distribution is still not fully explored.

Herring feeding migration in Arctic water can be explained by the same mechanism as suggested for herring feeding in Atlantic water, with herring following an increasing gradient of Calanus hyperboreus (Kroyer, 1838) into and in Arctic water. C. hyperboreus is an important prey of herring in Arctic and sub-arctic water (Dalpadado et al. 2000, Broms 2007) and plays a similar role in the Arctic food web as $C$. finmarchicus does in the Atlantic. In terms of biomass $C$. hyperboreus is the dominant Calanus sp. in Arctic water in the East Icelandic Current (Astthorsson \& Gislasson 2003) and the abundance of $C$. hyperboreus increases significantly from Atlantic to Arctic water (Broms et al. 2009). The progress in the bloom sequence and 
ascent of Calanus, proceeding from east to west, may also apply to Arctic water, and herring may take advantage of the high abundance of the overwintering generation of C. hyperboreus observed in Arctic water in the pre-bloom (Astthorsson \& Gislason 2003, Broms et al. 2009). The positive relation between herring and Calanus finmarchicus indicates that herring leave a specific area before their zooplankton prey are depleted. A rapid decrease in the abundance of female $C$. finmarchicus has been observed after spawning (Østvedt, 1965; Diel and Tande, 1992; Melle and Skjoldal, 1998). Predation by invertebrates, mesopelagic fish, and seasonal migrating fish (NSS herring, blue whiting and mackerel) may induce significant mortality on the C. finmarchicus population (Kaartvedt, 2000; Dale et al., 2001; Langøy et al., this volume). Copepod females are a preferred prey of visually feeding predators probably because of their size (Flinkman et al., 1992; Prokopchuk and Sentyabov, 2006). A rapid decrease in prey availability, due to high mortality of the overwintering population of $C$. finmarchicus, may cause the herring to soon leave the feeding areas and produce the positive relationship with $C$. finmarchicus abundance. However, the herring may not be the main predator causing reduction in $C$. finmarchicus abundance, except possibly locally.

The surveys in the present study did not fully cover the herring migration throughout the feeding season. Our objective was to find trends in the herring response to a number of important environmental variables. Spatially, the surveys covered large scale gradients into the core feeding area of herring (Fig. 2), which makes the data suitable for analysing relations between gradients and trends. The surveys also covered core areas during the feeding season (Fig. 2) and the trends will thus apply for important parts of the stock, even though we cannot conclude that the trends are valid for the whole population of mature herring. Temporally, the resolution is unique and covers much of the feeding season of herring. A good coverage of the seasonal aspect is important because we aim at relating the herring distribution to the seasonal development of Calanus finmarchicus, and not only to $C$. finmarchicus abundance. This means that to support a positive correlation between herring and $C$. finmarchicus, the herring must throughout the season migrate to new areas with high C. finmarchicus concentration since $C$. finmarchicus concentration within an area will change due to their seasonal development and possibly herring predation. Methodological circumstances may affect the observed association between herring and zooplankton abundance. Sampling stations must cover areas with both short and long herring predation histories, and zooplankton abundance associated with these. The surveys sampled extensive areas during the majority of the herring feeding season, and during the seasonal production cycle of Calanus finmarchicus. We assume that samples include newly invaded areas as well as areas with a longer herring predation history. The spatial scale used in the analyses may influence the predator-prey relation. Previous studies have identified scale-dependent spatial correlations between predators and their prey (e.g. Fairweather et al., 1984; Schneider and Piatt, 1986; Fairweather, 1988). We observed positive correlations over a 5 to $55 \mathrm{~nm}$. scale range with no significant differences between the spatial scales (not shown, Pearson's product moment correlation, bootstrapped 95\% confidence level). Herring schools and clusters of schools aggregate on a scale less than $5 \mathrm{~nm}$ (Misund, 1993; Mackinson et al., 1999), however, examining the impact of predation at the scale of a school was not the aim of the present study.

The overwintering generation of $C$. finmarchicus is probably more important than the first generation in influencing the herring feeding migration. Herring was associated to areas with high concentrations of $C$. finmarchicus, found in pre-bloom areas and thus belonging to the overwintering generation. The first generation of Calanus finmarchicus has probably minor influence on the feeding migration of old component herring, most likely due to low abundance of older stages available as prey. In the 
late phase of the feeding migration (July and August), herring probably switched to prey on the first generation of $C$. finmarchicus, which is dominant at this time of the year (Broms and Melle, 2007). This late feeding phase co-occurred with low densities of $C$. finmarchicus $\mathrm{CVI}$, mainly low abundance of $\mathrm{CV}$, and intermediate densities of CIV (Figure 5). Reduced abundance of $C$. finmarchicus $\mathrm{CVI}$ is due to the lack of a second generation in this region (Broms and Melle, 2007). Decreased abundance of $\mathrm{CV}$ is most probably explained by the seasonal descent of the overwintering stages of $C$. finmarchicus first generation in late summer in the north (Østvedt, 1955; Melle et al., 2004). From diet studies it has been observed that herring at this time had low average stomach contents mass and preyed on a wider variety of prey organisms compared to the main feeding season (Dalpadado et al., 2000; Langøy et al., this volume).

Food availability may not be the only factor affecting the feeding migration of NSS herring. A significant negative correlation was found between temperature and the abundance of herring. Migration from the spawning area to the Arctic front, and then northwards along the front, was constantly towards colder water. Inhabiting cold water reduces metabolic rates and may be better for growth if prey availability is low, due to conservation of energy (Brandt, 1993). In the herring's main feeding season, however, prey concentrations are in general high (Melle et al., 2004), and herring have been observed with remarkably high average stomach content weight and individuals have been judged as having completely full stomachs in cold Atlantic/Arctic water in northwestern Norwegian Sea (Broms, 2007). The migration trajectory towards colder water is thus probably the bioenergetic optimal path followed by the herring due to high food concentrations in the feeding areas, and not due to cold water temperature per se. Herring did not cross the Arctic front. Misund et al. $(1997,1998)$ observed that herring avoid water colder than $1-2^{\circ} \mathrm{C}$, indicating that there may be a temperature barrier that the herring do not cross, and that temperature influence herring migration at the scale of water masses.

The conclusions in the present study must be seen in light of these being based on data from a single year herring feeding season. Nevertheless, the present results support suggestions from Østvedt (1965), Melle et al. (1994) and Gislason \& Astthorsson (2002) that the migration of herring depends on the timing of the production cycle of Calanus finmarchicus. Seasonal dynamics of $C$. finmarchicus is in the present paper suggested to affect the spatial and temporal distribution of NSS herring during the feeding season. High densities of $C$. finmarchicus are vital to herring feeding success, and migration routes are probably tuned to densities and to the ascent of the overwintering $C$. finmarchicus population. The descent of $C$. finmarchicus in late summer co-occurs with reduced herring feeding success and motivation, and may initiate the return by herring to the overwintering area. The trophic link between Calanus finmarchicus and herring was viewed in a wider ecosystem perspective by exploring relationships between $C$. finmarchicus abundance and environmental variables related to phytoplankton production and hydrography. C. finmarchicus showed a stronger link to primary production and the physical environment than what was observed for herring (Figure 6, Table 3). Migration and distribution of herring may be indirectly connected to environmental variables through the seasonal development of $C$. finmarchicus population, which in turn is linked to biological and physical variables as chlorophyll a (as a proxy for phytoplankton dynamics) and temperature (Table 3, Broms and Melle, 2007). 


\section{Acknowledgements}

We would like to thank E. Bagøien, S. Kaartvedt and E. M. Olsen for valuable criticism on the manuscript, and colleagues at the IMR for help with the analysis of samples. We thank the Research Council of Norway for funding through projects $152906 / 120,155889 / \mathrm{S} 30$ and $178447 / \mathrm{S} 40$.

\section{Literature cited}

Anon., 1995. Reports on surveys of the distribution and migration of the Norwegian spring spawning herring and the environment of the Norwegian Sea and adjacent waters in the spring and summer of 1995. Report of ICES planning group for surveys on Norwegian spring spawning herring and the environment in the Norwegian Sea. 1153.

Astthorsson, O., Gislason, A. 2003. Seasonal variations in abundance, development and vertical distribution of Calanus finmarchicus, $C$. hyperboreus and $C$. glacialis in the East Icelandic Current. Journal of Plankton Research 25, 43-854.

Blindheim, J., 2004. Oceanography and climate. In: Skjoldal HR (ed) The Norwegian Sea ecosystem. Tapir Academic Press, Trondheim, 65-96.

Blindheim, J., Borovkov, V., Hansen, B., Malmberg, S-Aa., Turrell, WR., Østerhus, S., 2000. Upper layer cooling and freshening in the Norwegian Sea in relation to atmospheric forcing. Deep-Sea Research I 47, 655-680.

Brandt, S.B., 1993. The effect of thermal fronts on fish growth: A bioenergetics evaluation of food and temperature. Estuaries 16, 142-159.

Broms, C.T.Å, 2007. Distribution and life cycle of Calanus species in relation to the seasonal phytoplankton development and predator-prey interactions with Norwegian spring spawning herring in the physical setting of the Norwegian Sea ecosystem. Ph.D. Thesis, University of Oslo, Oslo, Norway. 1-73.

Broms, C., Melle, W., 2007. Seasonal development of Calanus finmarchicus in relation to phytoplankton bloom dynamics in the Norwegian Sea. Deep-Sea Research II 54, 2760-2775

Broms, C., Melle, W., Kaartvedt, S., 2009. Oceanic distribution and life cycle of Calanus species in the Norwegian Sea and adjacent waters. Deep Sea Research. 56,1910-1921.

Dale, T., Kaartvedt, S., Ellertsen, B., Amundsen, R., 2001. Large-scale oceanic distribution and population structure of Calanus finmarchicus, in relation to physical environment, food and predators. Marine Biology 139 (3), 561-574.

Dalpadado, P., Ellertsen, B., Melle, W., Dommasnes, A., 2000. Food and feeding conditions of Norwegian spring-spawning herring (Clupea harengus) through its feeding migrations. ICES Journal of Marine Science (4), 843-857.

Diel, S., Tande, K.S., 1992. Does the spawning of Calanus finmarchicus in high latitudes follow a reproduction pattern? Marine Biology 113, 21-31. 
Dragesund, O., Hamre, J., Ulltang, Ø., 1980. Biology and population dynamics of the Norwegian spring-spawning herring. Rapports et Procès-verbaux des Réunions, Conseil International Pour l'Exploration de la Mer 177, 43-71.

Dragesund, O., Johannessen, A., Ulltang, Ø., 1997. Variation in migration and abundance of Norwegian spring spawning herring (Clupea harengus L.). Sarsia 82, 97-105.

Fairweather, P.G., 1988. Correlations of predatory whelks with intertidal prey at several scales of space and time. Marine Ecology Progress Series 45, 237-243.

Fairweather, P.G., Underwood, A.J., Moran, M.J., 1984. Preliminary investigations of predation by the whelk Morula marginaiba. Marine Ecology Progress Series 17, 143156.

Fernö, A., Pitcher, T.J., Melle, W., Nøttestad, L., Mackinson, S., Hollingworth, C., Misund, O.A., 1998. The challenge of the herring in the Norwegian Sea: making optimal collective spatial decisions. Sarsia 83, 149-167.

Flinkman, J., Vuorinen, I., Aro, E., 1992. Planktivorous Baltic herring (Clupea harengus) prey selectively on reproducing copepods and cladocerans. Canadian Journal of Fisheries and Aquatic Sciences 49(1), 73-77.

Foote, K.G., 1987. Fish target strengths for use in echo integration surveys. Journal of the Acoustical Society of America 82(3), 981-987.

Gislason, A., Astthorsson, O.S., 2002. The food of Norwegian spring-spawning herring in the Western Norwegian Sea in relation to the annual cycle of zooplankton. Sarsia 87, 236-247.

Hagebø, M., Rey, F., 1984. Lagring av sjøvann til analyse av næringssalter (Storage of seawater for nutrients analysis.) Fisken Havet 4, 1-12

Hastie, T.J., Tibshirani, R.J., 1990. Generalized additive models. Chapman and Hall, London. $\mathrm{Pp} 352$.

Hind, A., Gurney, W.S., Heath, M., Bryant, H., 2000. Overwintering strategies in Calanus finmarchicus. Marine Ecology Progress Series 193, 95-107.

Hirche, H-J., 1996. Diapause in the marine copepod, Calanus finmarchicus - a review. Ophelia 44, 129-143.

Hirche, H-J., Brey, T., Niehoff, B., 2001. A high frequency time series at Ocean Weather Ship Station M (Norwegian Sea): population dynamics of Calanus finmarchicus. Marine Ecology Progress Series 219, 205-219.

Holst, J.C., Dragesund, O., Hamre, J., Misund, O.A., Østvedt, O.J., 2002. Fifty years of herring migrations in the Norwegian Sea. ICES Marine Science Symposia 215, 352-360.

Holst, J.C., Røttingen, I., Melle, W., 2004. The herring. In: Skjoldal HR (ed) The Norwegian Sea ecosystem. Tapir Academic Press, Trondheim, p 203-226. 
Holst, J.C., Slotte, A., 1998. Effects of juvenile nursery on geographic spawning distribution in Norwegian spring-spawning herring (Clupea harengus L.). ICES Journal of Marine Science 55, 987-996.

ICES Resource Management Committee 2003. Report of the Planning Group on Surveys on Pelagic Fish in the Norwegian Sea. ICES CM 2003/D:10, 1-62.

ICES 2008. Report of the Planning Group on Surveys on Pelagic Fish in the Norwegian Sea. ICES CM 2008/RMC:05, 1-83

ICES 2010. Report of the Working Group on Northeast Atlantic Pelagic Ecosystem Surveys (WGNAPES). ICES CM 2010/SSGESST:20, 1-92

Jakobsson, J., 1980. The North Icelandic herring fishery and environmental condition, 1960-1968. Rapp P-V Réun Cons Int Explor Mer 17:460-465

Kaartvedt, S., 2000. Life history of Calanus finmarchicus in the Norwegian Sea in relation to planktivorous fish. ICES Journal of Marine Science 57(6), 1819-1824.

Langøy, H., Nøttestad, L., Skaret, G., Broms, C., Fernö, A., 2011. Overlap in distribution and diets of Atlantic mackerel (Scomber scombrus), Norwegian springspawning herring (Clupea harengus) and blue whiting (Micromesistius poutassou) in the Norwegian Sea during late summer. Marine Biology Research, this volume.

Legendre, L., Legendre, P., 1983. Numerical Ecology. In: Jørgensen SE (ed) Developments in Environmental Modelling, Book 3. Elsevier scientific publishing company, Amsterdam, 1-18.

Mackinson, S., Nøttestad, L., Guénette, S., Pitcher, T., Misund, O.A., Fernö, A., 1999. Cross-scale observations on distribution and behavioural dynamics of ocean feeding Norwegian spring-spawning herring (Clupea harengus L.). ICES Journal of Marine Science 56, 613-626.

Melle, W., Ellertsen, B., Skjoldal, H.R., 2004. Zooplankton: The link to higher trophic levels. In: Skjoldal HR (ed) The Norwegian Sea ecosystem. Tapir Academic Press, Trondheim, 137-202.

Melle, W., Røttingen, I., Skjoldal, H.R., 1994. Feeding and migration of Norwegian spring spawning herring in the Norwegian Sea. ICES CM 1994/R:9, pp 25.

Melle, W., Skjoldal, H.R., 1998. Reproduction and development of Calanus finmarchicus, C.glacialis and C.hyperboreus in the Barents Sea. Marine Ecology Progress Series 169, 211-228.

Miller, C.B., Cowles, T.J., Wiebe, P.H., Copley, N.J., Grigg, H., 1991. Phenology in Calanus finmarchicus; hypotheses about control mechanisms. Marine Ecology Progress Series 72, 79-91.

Misund, O.A., 1993. Dynamics of moving masses: variability in packing density, shape, and size among herring, sprat, and saithe schools. ICES Journal of Marine Science 50, 145-160. 
Misund, O.A., Melle, W., Fernö, A., 1997. Migration behaviour of Norwegian spring spawning herring when entering the cold front in the Norwegian Sea. Sarsia 82, 107112.

Misund, O.A., Vilhjálmsson, H., Jákupsstovu, S.H., Røttingen, I., Belikov, S., Asthorsson, O., Blindheim, J., Jónsson, J., Krysov, A., Malmberg, S.A., Sveinbjørnsson, S., 1998. Distribution, migration and abundance of Norwegian spring spawning herring in relation to the temperature and zooplankton biomass in the Norwegian Sea as recorded by coordinated surveys in Spring and Summer 1996. Sarsia 83, 117-127.

Niehoff, B., Klenke, U., Hirche, H-J., Irigoien, X., Head, R., Harris, R., 1999. A high frequency time series at Weathership M, Norwegian Sea, during the 1997 spring bloom: The reproductive biology of Calanus finmarchicus. Marine Ecology Progress Series 176, 81-92.

Pavshtiks, E.A., Timokhina, A.F., 1972. History of investigations on plankton in the Norwegian Sea, and the main results of Soviet investigations. Proceedings of the Royal Society of Edinburgh (B) 73, 267-278.

Prokopchuk, I., Sentyabov, E., 2006. Diets of herring, mackerel, and blue whiting in the Norwegian Sea in relation to Calanus finmarchicus distribution and temperature conditions. ICES Journal of Marine Science 63, 117-127.

Rey, F., 2004. Phytoplankton: the grass of the sea. In: Skjoldal HR (ed) The Norwegian Sea ecosystem. Tapir Academic Press, Trondheim, 97-136.

Schneider, D.C., Piatt, J.F., 1986. Scale-dependent correlation of seabirds with schooling fish in a coastal ecosystem. Marine Ecology Progress Series 32, 237-246.

Skjoldal, H.R., 2004. The Norwegian Sea ecosystem. Tapir Academic Press, Trondheim, 1- 559.

Stenevik, E.K., Melle, W., Gaard, E., Gislason, A., Broms, C., Prokopchuk, I., Ellertsen, B., 2007. Eggproduction of Calanus finmarchicus - A basin-scale study. Deep-Sea Research II 54, 2672-2685

Timokhina, A.F., 1964. On zooplankton production in different water masses of the Norwegian Sea. Trudy PINRO 16, 165-182.

Toresen, R., Østvedt, O.J., 2000. Variation in abundance of Norwegian springspawning herring (Clupea harengus, Clupeidae) throughout the $20^{\text {th }}$ century and the influence of climatic fluctuations. FISK and FISHERIES 1, 231-256.

Valdemarsen, J.W., Misund, O.A., 1995. Trawl designs and techniques used by Norwegian research vessels to sample fish in the pelagic zone. In: Hylen A (ed) Proceedings of the sixth IMR-PINRO Symposium. Institute of Marine Research, Bergen, 135-144.

Wiborg, K.F., 1954. Investigations on zooplankton in coastal and offshore waters of western and northwestern Norway. Fiskeridirektoratets Skrifter (Serie Havundersøkelser) 11, 1-246.

Wiborg, K.F., 1955. Zooplankton in relation to hydrography in the Norwegian Sea. Fiskeridirektoratets Skrifter (Serie Havundersøkelser)11, 1-66. 
Wood SN. 2003. Thin plate regression splines. Journal of the Royal Statistical Society B, 65: 95-114.

Wood SN. 2006. Generalized additive models: An Introduction with R. Chapman and Hall/CRC. Pp 392.

Zuur AF, leno EN, Smith GM. 2007. Analysing Ecological Data. Springer Science + Business Media, LLC, USA. 1- 672.

Zuur AF, leno EN, Walker NJ, Saveliev AA, Smith GM. 2009. Mixed Effects Models and Extensions in Ecology with R. Springer Science + Business Media, LLC, USA. 1574.

Østvedt, O.J., 1955. Zooplankton investigations from weathership $M$ in the Norwegian Sea 1948-49. Hvalrådets Skrifter 40, 1-93.

Østvedt, O.J., 1965. The migration of the Norwegian herring to Icelandic waters and the environmental conditions in May-June, 1961-1964. Fiskeridirektoratets Skrifter (Serie Havundersøkelser)13, 29-47 


\section{Tables}

Table 1. Variables considered important in affecting the feeding migration of NSS herring and thus used in the analyses. The reasoning for selecting these particular variables is given.

Variables

Day of year

Latitude

Longitude

Calanus finmarchicus abundance

Zooplankton biomass fraction 1

Zooplankton biomass fraction 2

Zooplankton biomass fraction 3

Temperature

Salinity

Consumed nitrate
Reasoning for selecting these variables in analyses Light intensity and day length differ during the season, and the plankton production develops with time.

Indicates north-south difference in environmental variables and prey density, and may represent predictive large-scale variations in herring migration.

Indicates east-west differences in environmental variables and prey density, and may represent predictive large-scale variations in herring migration. Respresent water mass due to the north-south distribution of fronts between the water masses in the Norwegian Sea (Figure 1).

Main prey of herring and the ascent and development of the overwintering population follows a pattern similar to the historical herring feeding migration pattern.

Prey of herring. Contains zooplankton prey larger than $2000 \mu$, as krill, amphipods, Euchaeta spp., C. hyperboreus.

Referred to as "Biomass fraction 1".

Prey of herring. Contains zooplankton prey smaller than $2000 \mu$ and larger than $1000 \mu$, as $C$. finmarchicus copepodite stage IV-VI, Metridia spp.

Referred to as "Biomass fraction 2".

Potential prey of herring. Contains zooplankton prey smaller than $1000 \mu$ and larger than $180 \mu$, as $C$. finmarchicus copepodite stage I-IIII, Oithona spp., Acartia spp. However this size group may be too small as herring prey, and not reported as important as biomass fraction 1 and 2 . Referred to as "Biomass fraction 3".

Affects metabolism and thereby growth. Herring may have a physiological temperature optimum and barriers.

Herring may have a physiological salinity optimum and barriers.

Not assumed to influence herring migration directly, but indirectly by being indicators of the development of the primary production and thus $C$. finmarchicus development. Only used in analyses with $C$. finmarchicus as response variable. 
Table 2.Generalized additive models of Norwegian spring spawning herring abundance as response to environmental variables. Herring abundance, Calanus finmarchicus abundance and biomass fractions are transformed using a log $(x+1)$ transformation. edf $=$ effective degrees of freedom, the higher the edf the more non-linearity in the smoothing spline, GCV = generalized cross validation, compromise between roughness and smoothness of a fitted curve. $s=$ thin plate regression spline, used as smoother. Number of sampling stations is 38.

${ }^{*} \mathrm{p}<0.05, \mathrm{~ns}=$ not significant

\begin{tabular}{|c|c|c|c|c|}
\hline Generalized additive models (GAM) & edf & GCV & deviance explained (\%) & $\mathrm{p}$-value \\
\hline Herring $=s($ Day of year $)$ & 1.00 & 3.06 & 9.2 & ns \\
\hline Herring $=s($ Latitude $)$ & 1.00 & 3.36 & 0.1 & ns \\
\hline Herring $=s($ Longitude $)$ & 1.00 & 2.94 & 12.7 & $*$ \\
\hline Herring $=s(C$. finmarchicus $\mathrm{CV}$ and $\mathrm{CVI})$ & 2.40 & 2.80 & 23.3 & $*$ \\
\hline Herring $=s($ Biomass fraction 1$)$ & 1.00 & 3.10 & 8.0 & ns \\
\hline Herring $=s($ Biomass fraction 2$)$ & 1.00 & 2.93 & 13.1 & ns \\
\hline Herring $=s($ Biomass fraction 3$)$ & 4.88 & 3.17 & 25.1 & ns \\
\hline Herring $=s($ Temperature $)$ & 1.03 & 2.86 & 15.2 & $*$ \\
\hline Herring $=s($ Salinity $)$ & 1.00 & 3.23 & 4.1 & ns \\
\hline Herring $=s($. finmarchicus $\mathrm{CV}$ and $\mathrm{CVI})+s($ Biomass fraction 3$)+s($ Temperature $)$ & & 2.65 & 51.0 & \\
\hline
\end{tabular}


Table 3. Generalized additive models of Calanus finmarchicus copepodite stage CV and CVI abundance as response to environmental variables. C. finmarchicus abundance and chlorophyll a are transformed using a log $(x+1)$ transformation. edf $=$ effective degrees of freedom, the higher the edf the more non-linearity in the smoothing spline, GCV = generalized cross validation, compromise between roughness and smoothness of a fitted curve. $s=$ thin plate regression spline, used as smoother. Number of sampling stations is 38 .

${ }^{* *} p<0.01,{ }^{* * *} p<0.001, n s=$ not significant

\begin{tabular}{|c|c|c|c|c|}
\hline Generalized additive models (GAM) & edf & GCV & deviance explained (\%) & $\mathrm{p}$-value \\
\hline C. finmarchicus $=\mathrm{s}($ Day of year $)$ & 1.67 & 0.49 & 46.9 & $* * *$ \\
\hline C. finmarchicus $=\mathrm{s}($ Latitude $)$ & 1.00 & 0.72 & 17.8 & $* *$ \\
\hline C. finmarchicus $=s($ Longitude $)$ & 1.00 & 0.50 & 43.3 & $* * *$ \\
\hline C. finmarchicus $=s($ Salinity $)$ & 1.87 & 0.82 & 10.8 & ns \\
\hline C. finmarchicus $=s($ Consumed nitrate $)$ & 1.00 & 0.69 & 21.7 & $* *$ \\
\hline C. finmarchicus $=s($ Chlorophyll $a)$ & 1.41 & 0.45 & 50.1 & $* * *$ \\
\hline
\end{tabular}




\section{Figures}

Figure 1. Map of the study area. Circles represent CTD, nutrients, chlorophyll a, zooplankton, and herring trawl stations. Open circles denote stations with the acoustic registration of herring being zero. Solid black lines represent the 35 isohaline at $20 \mathrm{~m}$ depth based on combined salinity values from June and July using inverse distance weighting (IDW) as interpolation method (144 stations). The isohalines do not represent the exact position of the Atlantic and Arctic fronts at any given time.

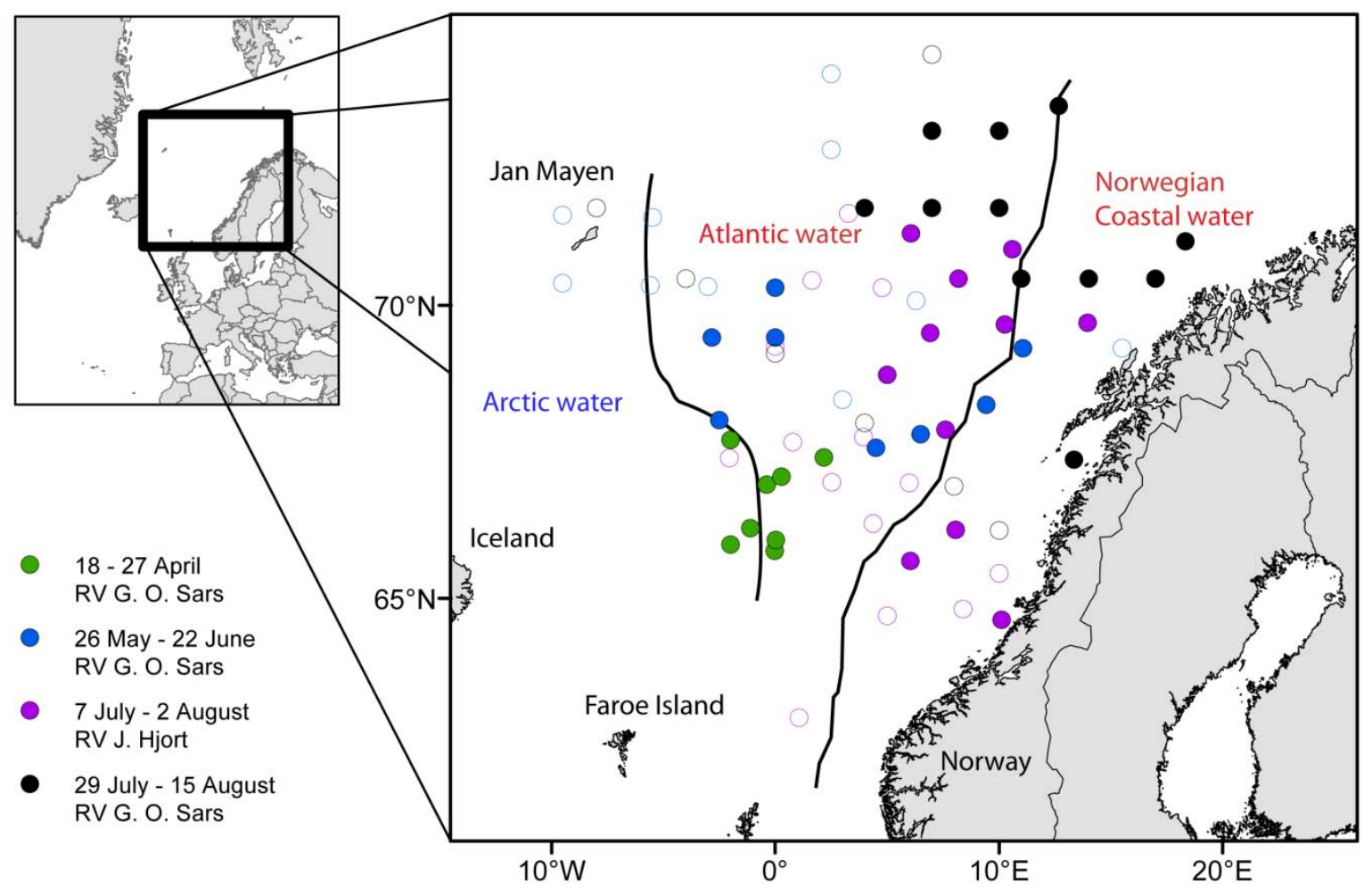


Figure 2. Distribution of Norwegian spring spawning herring within the survey areas in the Norwegian Sea in April (a), end of May and June (b), July (c) and August (d) as $\mathrm{s}_{\mathrm{A}}$-values averaged over $5 \mathrm{nmi}$ along the survey lines. Several year classes of herring could be found at each trawl station. The average age per station grouped into herring $<5$ years and herring $\geq 5$ years is given. Solid black lines represent the Arctic front.
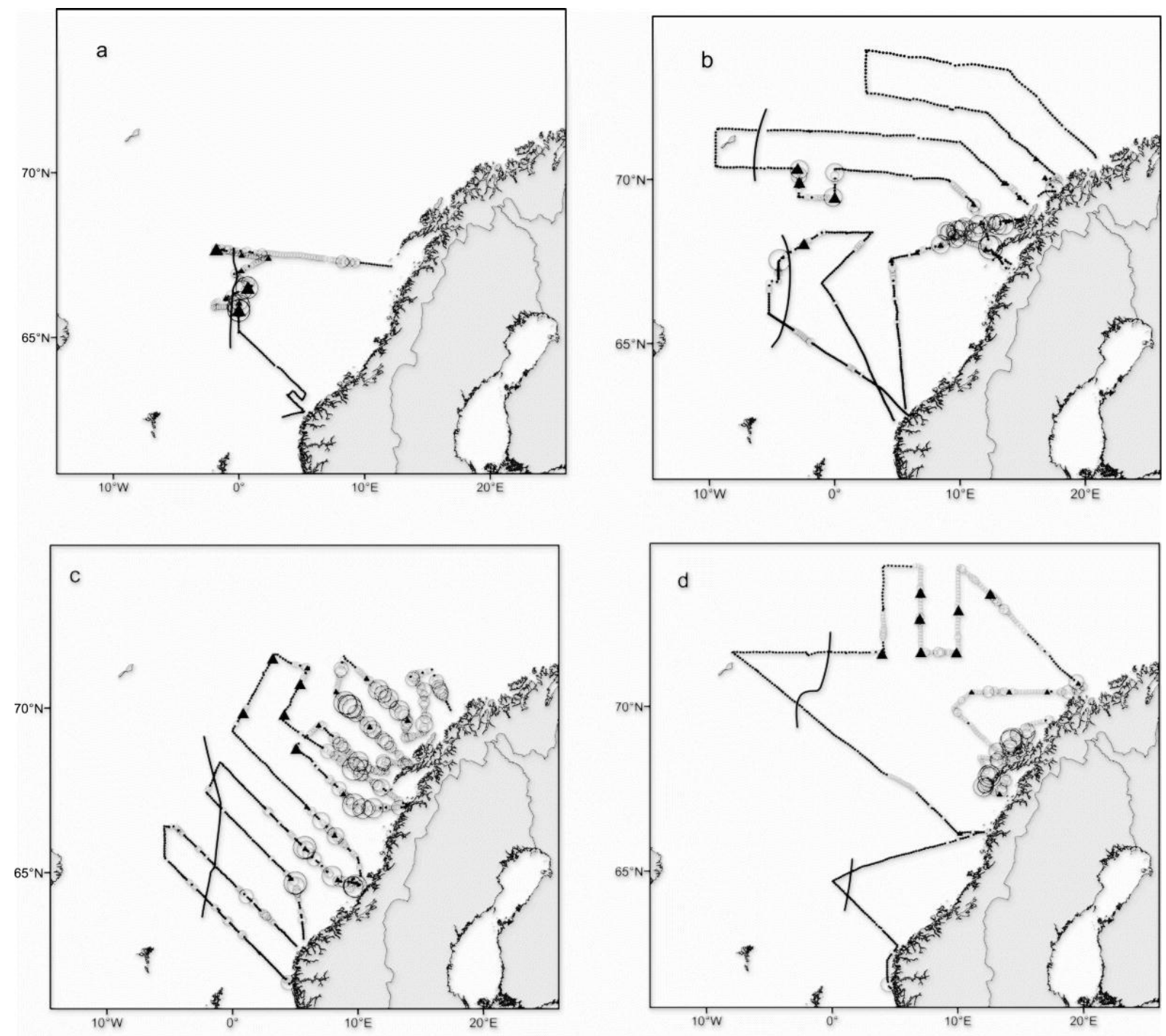

Herring $\mathrm{s}_{\mathrm{A}}$ - values $\left(\mathrm{m}^{2} \mathrm{nmi}^{-2}\right)$

Average herring age
(year) per trawl station
0
$0.1-200$
$200-400$
$400-600$
$600-800$
$800-1000$
$1000-2000$
$2000-4000$
$4000-6000$
$6000-8000$
$8000-10000$
$>10000$

- $<5$ 
Figure 3. Effects of environmental variables on herring abundance during herring feeding migration, as predicted from GAM models in Table 2. Herring abundance is given as number of herring per square nautical mile, averaged over 5 nautical miles. Shaded area marks the $95 \%$ confidence level around the mean prediction.

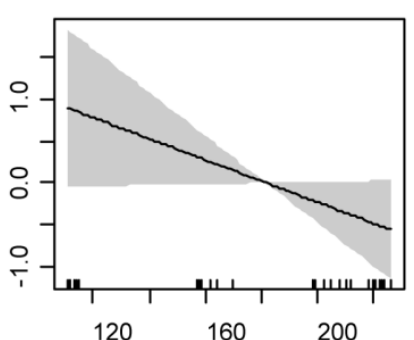

Day of the year
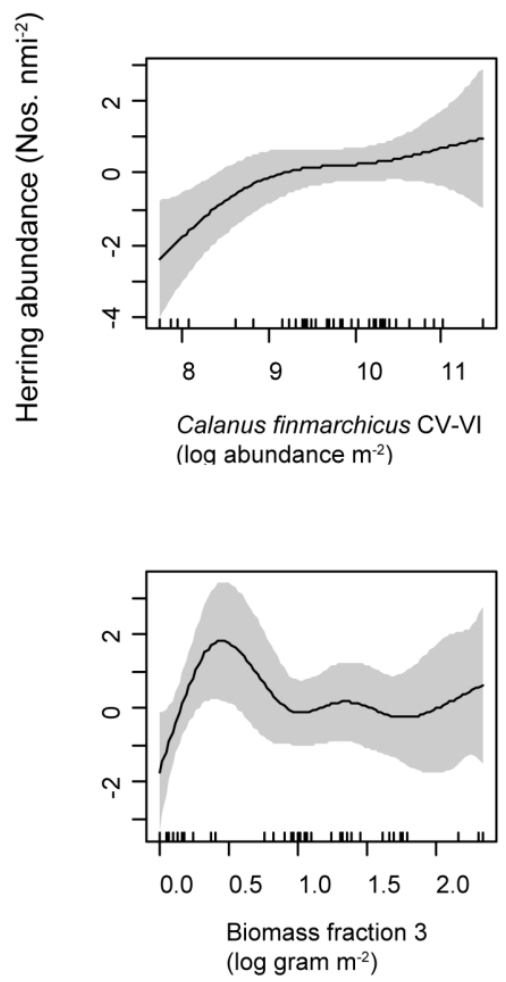
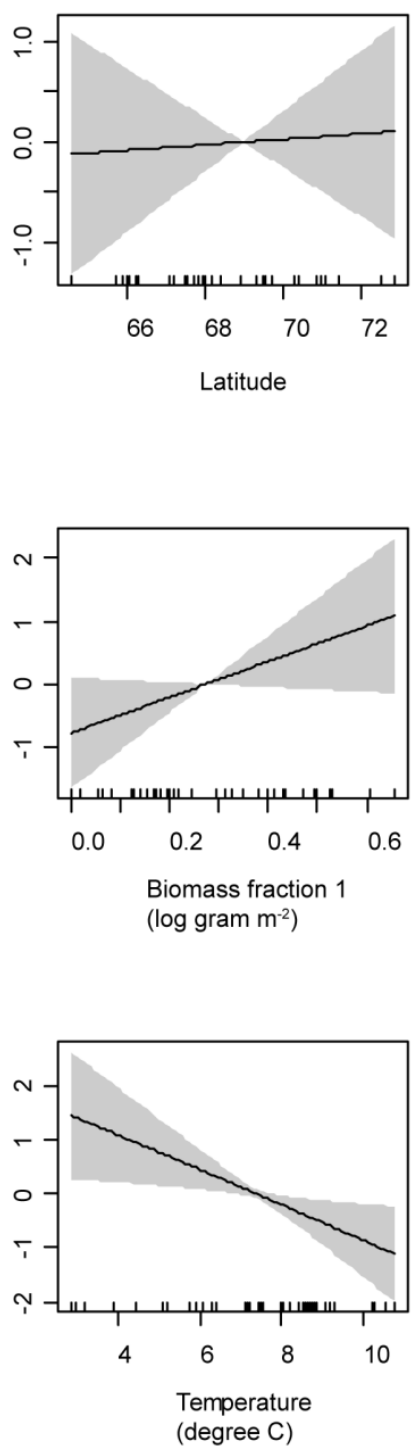
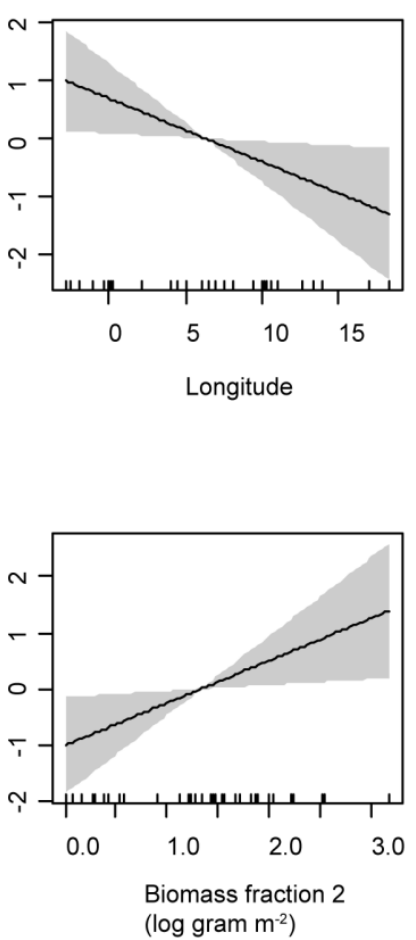

$\left(\log\right.$ gram $\mathrm{m}^{-2}$ )

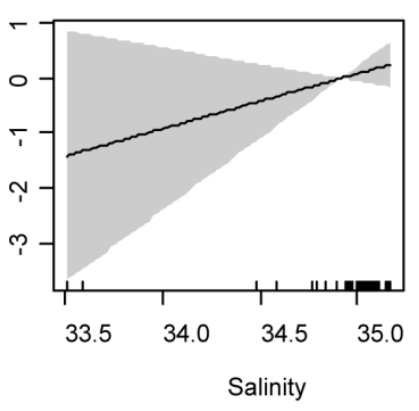


Figure 4. Effects of a) Calanus finmarchicus CV-VI abundance, (edf $=2.3$ ), b) biomass fraction 3 (zooplankton biomass within size-interval $180-1000 \mu$, edf $=5.3$ ), and $\mathrm{c}$ ) temperature (edf $=1.0$ ) on herring abundance, as predicted from multiple GAM model in Table 2 . Shaded area marks the $95 \%$ confidence level around the mean prediction.

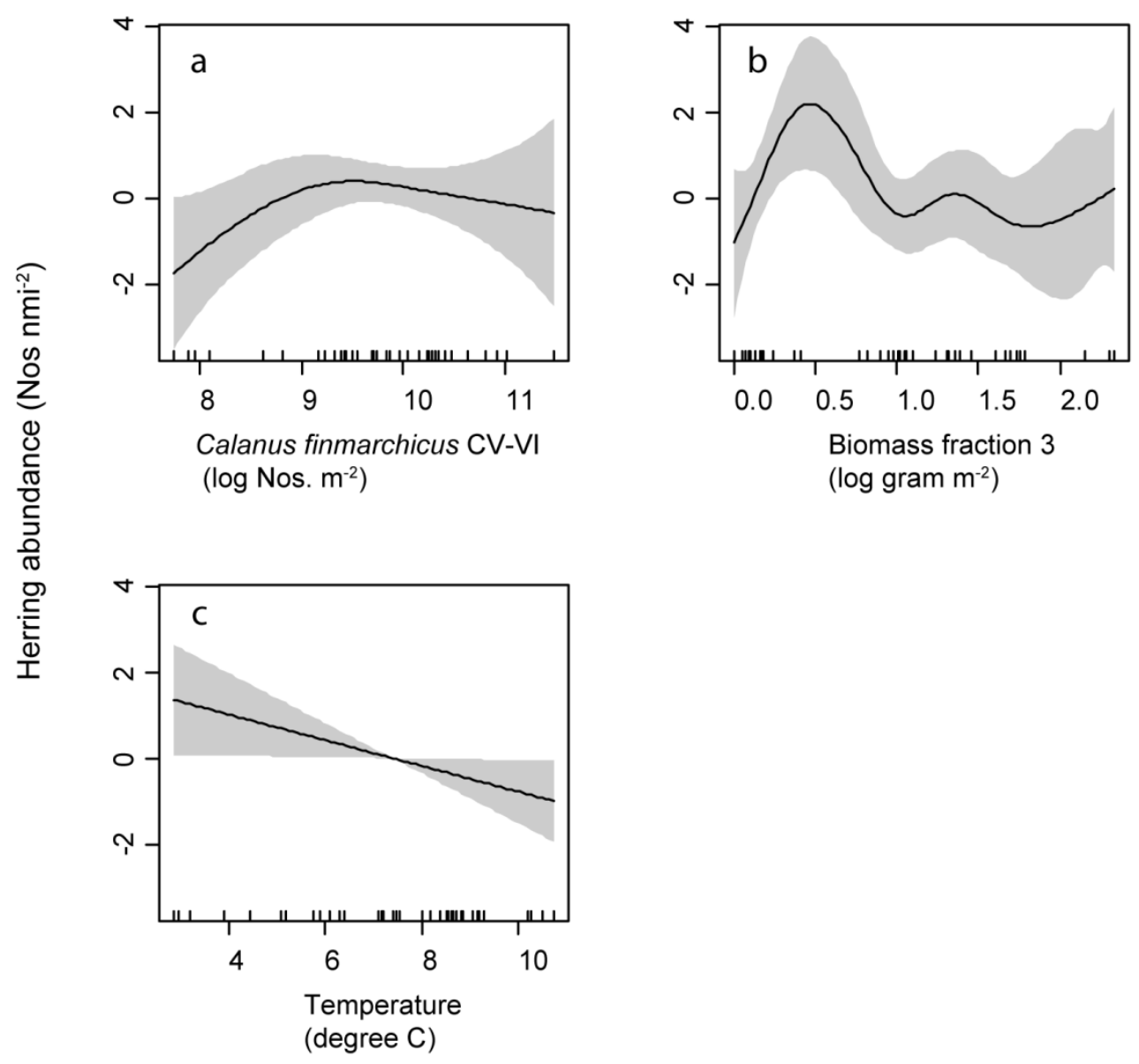

Figure 5. Effects of Day of the year on Calanus finmarchicus copepodite stage IV, V, and VI, as predicted from GAM models, showing the seasonal development of older stages of $C$. finmarchicus in the herring feeding area.

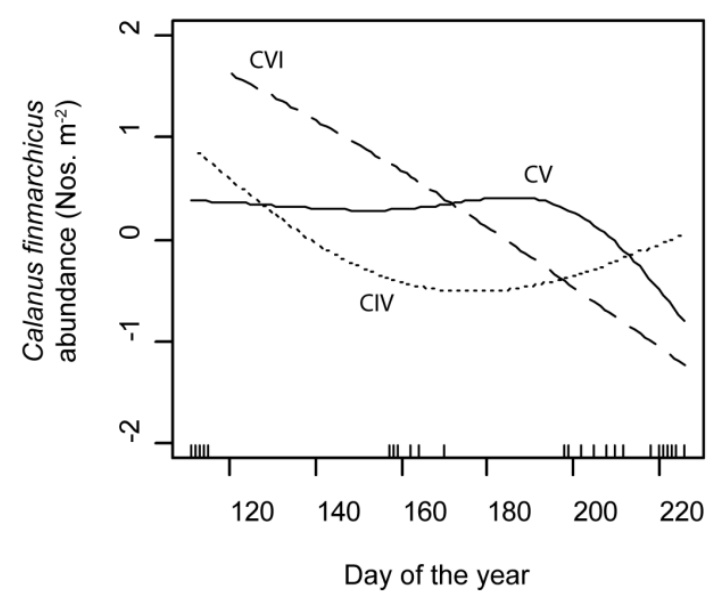


Figure 6. Effects of environmental variables on Calanus finmarchicus CV-VI abundance, as predicted from GAM models in Table 3, within the herring feeding area. Shaded area marks the $95 \%$ confidence level around the mean prediction.
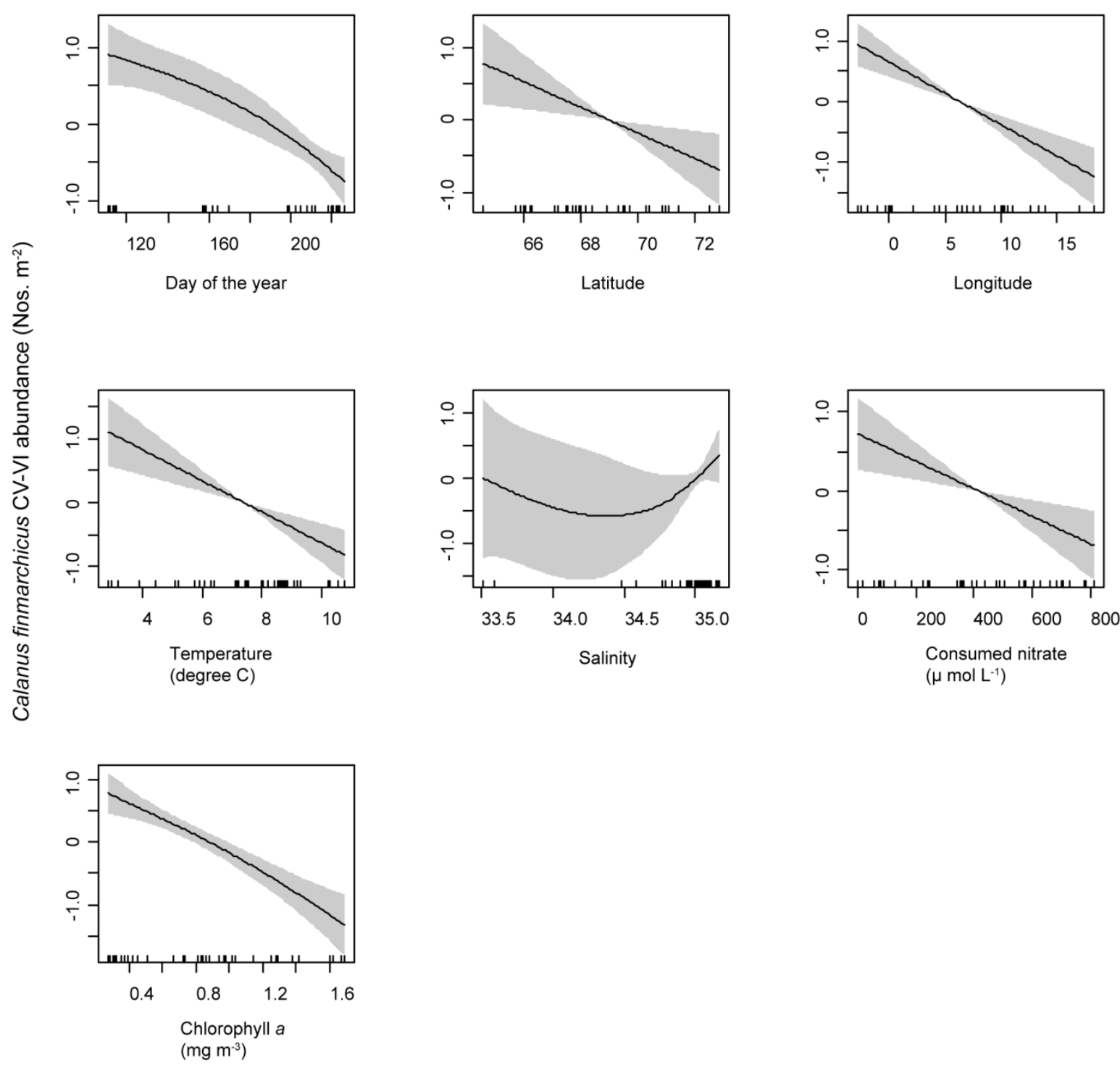